\title{
DOSE DE NITROGÊNIO ASSOCIADA À PRODUTIVIDADE DE BATATA E ÍNDICES DO ESTADO DE NITROGÊNIO NA FOLHA ${ }^{(1)}$
}

\author{
Fabrício Silva Coelho ${ }^{(2)}$, Paulo Cezar Rezende Fontes ${ }^{(3)}$, Mário \\ Puiatti $^{(4)}$, Júlio César Lima Neves ${ }^{(5)} \&$ Marcelo Cleón de Castro \\ Silva ${ }^{(6)}$
}

\begin{abstract}
RESUMO
O nitrogênio é um dos elementos de grande impacto na produtividade da batata, e seu efeito nas plantas pode ser avaliado por meio de técnicas de diagnóstico do estado nutricional. Este trabalho teve o objetivo de determinar a dose ótima econômica de $\mathrm{N}$ para a produção de tubérculos e estimar o nível crítico de índices do estado de $\mathrm{N}$ na folha de duas cultivares de batata. $\mathrm{O}$ experimento foi conduzido de maio a agosto de 2008 , em delineamento em blocos ao acaso em esquema fatorial $4 \times 2$, sendo quatro doses de $N\left(0,100,200\right.$ e $400 \mathrm{~kg} \mathrm{ha}^{-1}$ de $\mathrm{N}$, aplicadas em préplantio como ureia) e duas cultivares de batata (Ágata e Asterix), com quatro repetições. Aos 21 dias após a emergência foram determinadas a leitura SPAD e os teores de $\mathrm{N}$ e de clorofila na quarta folha a partir do ápice (QF). A produtividade de tubérculos comerciais aumentou até 45.065 e $46.500 \mathrm{~kg} \mathrm{ha}^{-1} \mathrm{com}$ o aumento da dose de $\mathrm{N}$ até 297 e $250 \mathrm{~kg} \mathrm{ha}^{-1}$ para Ágata e Asterix, respectivamente. Para essas cultivares, a dose para obtenção da máxima eficiência econômica foi de 290 e $245 \mathrm{~kg} \mathrm{ha}^{-1}$ de $\mathrm{N}$, respectivamente. Nas duas cultivares, houve efeito positivo de doses de $\mathrm{N}$ sobre o índice SPAD e teores de $\mathrm{N}$ e de clorofila na QF. Os valores críticos foram de 40,5 e 43,7 para o índice $S P A D$, de 66,7 e $75,2 \mathrm{~g} \mathrm{~kg}^{-1}$ para o teor foliar de $\mathrm{N}$ e de 6,13 e $6,96 \mathrm{mg} \mathrm{g}^{-1}$ para o teor de clorofila total na matéria fresca das folhas, respectivamente, para Ágata e Asterix. Os valores da leitura do índice SPAD correlacionaram-se com os valores de clorofila total extraível na quarta
\end{abstract}

\footnotetext{
(1) Recebido para publicação em maio de 2009 e aprovado em abril de 2010.

(2) Doutorando de Pós-Graduação em Fitotecnia, Departamento de Fitotecnia, Universidade Federal de Viçosa - UFV. Av. PH Rolfs, s/n. Campus Universitário. CEP 36570-000 Viçosa (MG). Bolsista CNPq. E-mail: fabriufla@yahoo.com.br

(3) Professor Titular do Departamento de Fitotecnia, UFV. Bolsista CNPq. E-mail: pacerefo@ufv.br

(4) Professor Associado do Departamento de Fitotecnia, UFV. E-mail: mpuiatti@ufv.br

(5) Professor Adjunto do Departamento de Solos, UFV. E-mail: julio_n2003@yahoo.com.br

${ }^{(6)}$ Pós-Doutorando, Departamento de Fitotecnia, UFV. E-mail: mdecastro70@yahoo.com.br
} 
folha e com a produção de tubérculos de batata, indicando a possibilidade de medir o valor SPAD aos 21 DAE para prognosticar a produtividade de tubérculos de batata.

Termos de indexação: Solanum tuberosum L., fertilização nitrogenada, teor de nitrogênio, leitura SPAD.

\title{
SUMMARY: NITROGEN RATE ASSOCIATED WITH YIELD OF POTATOAND LEAF NITROGEN INDICES
}

\begin{abstract}
Nitrogen has strong impact on potato yield and its effects on plants can be evaluated by specific nutritional diagnostic techniques. The objective of this work was to determine the optimum economical $N$ rate for tuber yield and to estimate the critical value of plant $N$ indices in leaf of two potatoes cultivars. The experiment had a $4 x 2$ factorial in a completely randomized block design with four replications, with four $N$ levels $\left(0,100,200\right.$ e $400 \mathrm{~kg} \mathrm{ha}^{-1}$ of $\mathrm{N}$, preplanting applied as urea) and two potato cultivars (Ágata e Asterix), from April to June 2008. $S P A D$ reading values, nitrogen and chlorophyll contents were determined in the fourth leaf from the apex 21 days after plant emergence. Marketable tuber yield of Ágata and Asterix increased up to 45,065 e 46,500 $\mathrm{kg} \mathrm{ha}^{-1}$ as $\mathrm{N}$ rates increased up to 297 and $250 \mathrm{~kg} \mathrm{ha}^{-1}$ for Agata and Asterix, respectively. The maximum economic efficiency rate of these cultivars was 290 and $245 \mathrm{~kg} \mathrm{ha}^{-1}$ of $\mathrm{N}$, respectively. For both cultivars, the $N$ effect on SPAD values, nitrogen and chlorophyll contents were positive and significant. Critical values were 40.5 and 43.7 for SPAD readings, 66.7 and $75.2 \mathrm{~g} \mathrm{~kg}^{-1}$ for leaf $N$ concentration, and 6.13 and $6.96 \mathrm{mg} \mathrm{g}^{-1}$ for total leaf chlorophyll contents, respectively, for Agata and Asterix. The SPAD reading values correlated with the values of extractable total chlorophyll in the fourth leaf and potato tuber yields at the final harvest, indicating the possibility of using SPAD measurement at 21 days after plant emergence to prognostic final potato tuber yield.
\end{abstract}

Index terms: Solanum tuberosum $L$., nitrogen fertilization, $N$ content, SPAD index.

\section{INTRODUÇÃO}

Para a produção de batata (Solanum tuberosum L.) é necessário haver adequado suprimento de nutrientes, entre os quais o N, que é um dos elementos de maior impacto na produtividade da cultura, por estimular o crescimento vegetativo da planta (Yin et al., 2003). Contudo, devem ser evitadas doses excessivas, principalmente as aplicadas tardiamente, que induzem a planta a produzir folhas em demasia e a alongar seu crescimento e maturação, o que implica redução do período desejável de tuberização e, consequentemente, menor armazenagem de amido nos tubérculos, resultando em menor produtividade e qualidade do tubérculo (Zvomuya et al., 2003).

A forma mais comumente utilizada para o fornecimento de $\mathrm{N}$ à batateira é a aplicação de $\mathrm{N}$ mineral via fertilizantes. No Brasil, é possível encontrar recomendações de fertilização variando de 60 a $250 \mathrm{~kg} \mathrm{ha}^{-1}$ de N (Fontes, 1999); a dose ótima a ser fornecida depende de vários fatores, como produtividade esperada, pluviosidade, cultura anterior, práticas culturais, entre outros (Fontes, 2001). Além disso, a dose a ser aplicada deve otimizar o rendimento da cultura e a qualidade final do produto, maximizar a rentabilidade e reduzir os riscos de contaminação ambiental (Bélanger et al., 2000).
Com a elevação no custo dos fertilizantes nitrogenados, os agricultores necessitam adequar o manejo da adubação. Entretanto, aplicações de doses muito baixas ou demasiadamente elevadas reduzirão os lucros. Assim, a taxa mais rentável de aplicação de $\mathrm{N}$ deve ser ajustada aos preços da batata e do fertilizante, com a finalidade de otimizar o uso de insumos e de minimizar os riscos com a produção e comercialização.

Para avaliar o efeito do $\mathrm{N}$ nas plantas ou a adequação do programa de adubação para as culturas, podem ser utilizadas técnicas de diagnóstico do estado nutricional. Entre os índices de N mais comuns, temse o teor de N-total ou orgânico na matéria seca da folha ou parte da folha, a massa de matéria seca da planta, o teor e a quantidade de $\mathrm{N}$ acumulada e a intensidade da cor verde da folha (Fontes \& Araújo, 2007). Normalmente, esses índices são interpretados utilizando-se o critério de concentração ou faixa crítica de concentração (Gil, 2001).

A cor verde das plantas está diretamente associada com o teor de clorofila foliar, e este, altamente relacionado com o teor de $\mathrm{N}$ na maioria das plantas. Os pigmentos fotossintéticos (clorofilas $a, b$ e total e carotenóides) são essenciais para o desenvolvimento das plantas, pois são responsáveis pela captura da energia solar usada na fotossíntese (Taiz \& Zeiger, 
2009). Assim, plantas cultivadas com quantidades inadequadas de N normalmente não expressam o seu potencial produtivo, visto que, sob tais condições, podem ocorrer reduções significativas na taxa assimilatória líquida de $\mathrm{CO}_{2}$, já que o $\mathrm{N}$ faz parte dos principais componentes do sistema fotossintético, como as clorofilas e as enzimas ribulose 1,5 bisfosfato carboxilase/oxigenase (Rubisco) e fosfoenolpiruvato carboxilase (PEPcase).

No entanto, a possibilidade de se utilizar um índice da planta como indicador da adequação da dose do fertilizante nitrogenado não tem sido explorada, pois os métodos tradicionais de avaliação do estado nutricional são demorados e onerosos. Normalmente, a dose de $\mathrm{N}$ ainda tem sido estabelecida por meio de curvas de resposta obtidas no campo, ao contrário dos demais macronutrientes, cuja limitação pode ser prevista pela análise do solo (Coelho \& Fontes, 2005). Atualmente, tem sido proposto o uso de medidores portáteis, denominados clorofilômetros, para avaliar o estado de $\mathrm{N}$ da planta em tempo real, pela análise da intensidade do verde das folhas. Um desses medidores portáteis é o SPAD-502, que apresenta facilidade de operação, permite avaliações in situ e já foi utilizado com sucesso em feijão (Madeira et al., 2000), milho (Argenta et al., 2001), algodão-herbáceo (Neves et al., 2005), amendoim (Samdur et al., 2000) e melão (Azia \& Stewart, 2001) como indicador indireto do status de $\mathrm{N}$ da planta. No caso da cultura da batata, Vos \& Bom (1993) verificaram alta correlação das leituras do clorofilômetro SPAD com as determinações analíticas de clorofila e da concentração de $\mathrm{N}$ nas folhas.

Este trabalho teve como objetivos determinar a dose ótima de $\mathrm{N}$ associada à máxima produtividade física e econômica de tubérculos de cultivares de batata e estimar o valor crítico de índices do estado de $\mathrm{N}$ da planta.

\section{MATERIAL E MÉTODOS}

O experimento foi realizado na Horta de Pesquisas do Departamento de Fitotecnia (DFT) da Universidade Federal de Viçosa (UFV), na época de outono/inverno (maio a agosto de 2008). O município de Viçosa apresenta altitude de $693 \mathrm{~m}$, latitude sul de $20^{\circ} 45^{\prime}$, longitude oeste de $42^{\circ} 51^{\prime}$ e classificação climática de Köppen (1948) do tipo Cwa, caracterizado pelo clima tropical de altitude, com chuvas no verão e seca no inverno. A temperatura média do ar durante o período experimental foi de $17,9^{\circ} \mathrm{C}$; a média das temperaturas mínimas, de $13,2{ }^{\circ} \mathrm{C}$; e a média das temperaturas máximas, de $25,5^{\circ} \mathrm{C}$. Os dados climáticos foram coletados diariamente na estação meteorológica da UFV, localizada a $3 \mathrm{~km}$ da área experimental.

Anteriormente à instalação do experimento, a área experimental foi cultivada com milho, sem utilização de adubo nitrogenado, com o objetivo de reduzir o $\mathrm{N}$ disponível no solo. Após a retirada do milho, foram coletadas amostras de solo das camadas de 0-20 e 20$40 \mathrm{~cm}$ de profundidade, para determinação das características químicas (Quadro 1). O solo da área experimental foi classificado como Argissolo VermelhoAmarelo eutrófico (Embrapa, 1999).

O delineamento experimental foi o de blocos ao acaso, em esquema fatorial $4 \times 2$, sendo quatro doses de $\mathrm{N}\left(0,100,200\right.$ e $\left.400 \mathrm{~kg} \mathrm{ha}^{-1}\right)$, aplicadas em préplantio, e duas cultivares de batata (Ágata e Asterix), com quatro repetições. Como fonte de $\mathrm{N}$ foi utilizada a ureia (44\% de N).

Cada parcela foi constituída de quatro fileiras com 10 plantas, espaçadas de $0,75 \mathrm{~m}$ entre fileiras e $0,25 \mathrm{~m}$ entre plantas, com dimensões de $2,5 \mathrm{~m}$ de comprimento e 3,0 m de largura. Consideraram-se como bordaduras as duas fileiras laterais e as duas plantas das extremidades das fileiras centrais, restando 16 plantas úteis por parcela.

O preparo do solo consistiu de aração, com arado de aiveca, e de duas passagens de grade niveladora. A adubação, feita manualmente no sulco de plantio, consistiu de $1.800 \mathrm{~kg} \mathrm{ha}^{-1}$ de superfosfato simples (18\% de $\left.\mathrm{P}_{2} \mathrm{O}_{5}\right), 384 \mathrm{~kg} \mathrm{ha}^{-1}$ de cloreto de potássio (60\% de $\mathrm{K}_{2} \mathrm{O}$ ), $200 \mathrm{~kg} \mathrm{ha}^{-1}$ de sulfato de magnésio (10\% de $\mathrm{Mg}), 10 \mathrm{~kg} \mathrm{ha}^{-1}$ de bórax (10\% de B), $10 \mathrm{~kg} \mathrm{ha}^{-1} \mathrm{de}$ sulfato de zinco (20\% de $\mathrm{Zn}), 10 \mathrm{~kg} \mathrm{ha}^{-1}$ de sulfato de cobre (24\% de Cu) e 0,5 $\mathrm{kg} \mathrm{ha}^{-1}$ de molibdato de sódio (39 \% de Mo).

O plantio foi realizado no dia 9/05/2008, utilizandose batatas-semente de tamanho uniforme, previamente brotadas e com peso médio de $60 \mathrm{~g}$. A cultura foi conduzida segundo as recomendações de

Quadro 1. Características químicas do solo nas camadas de 0-20 e 20-40 cm de profundidade, antes da instalação do experimento

\begin{tabular}{|c|c|c|c|c|c|c|c|c|c|c|c|}
\hline Camada & $\mathrm{pH} \mathrm{H}_{2} \mathrm{O}$ & $\mathbf{P}$ & $\mathbf{K}^{+}$ & $\mathrm{Ca}^{2+}$ & $\mathrm{Mg}^{2+}$ & $\mathrm{Al}^{3+}$ & $\mathbf{H}+\mathbf{A l}$ & CTC $_{\text {total }}$ & $\mathrm{V}$ & $\mathbf{m}$ & MO \\
\hline & & \multicolumn{2}{|c|}{$-\mathrm{mg} \mathrm{dm}^{-3}-$} & \multicolumn{5}{|c|}{$-\mathrm{cmol}_{\mathrm{c}} \mathrm{dm}^{-3}$} & \multicolumn{2}{|c|}{ — $\%$} & $\mathrm{~g} \mathrm{~kg}^{-1}$ \\
\hline $0-20 \mathrm{~cm}$ & 6,0 & 78,3 & 196 & 4,6 & 0,9 & 0,0 & 3,0 & 9,1 & 67,0 & 0,0 & 41 \\
\hline $20-40 \mathrm{~cm}$ & 5,8 & 70,1 & 80 & 3,4 & 0,6 & 0,0 & 3,0 & 7,2 & 58,5 & 0,0 & 28 \\
\hline
\end{tabular}

P-K: extrator Mehlich-1; Ca-Mg-Al: extrator $\mathrm{KCl} 1 \mathrm{~mol} \mathrm{~L}^{-1}$; $\mathrm{H}+\mathrm{Al}$ : Extrator Acetato de Cálcio 0,5 mol L'1; MO: Walkley-Black. 
manejo descritas por Fontes (2005), com controle fitossanitário realizado com os defensivos químicos carbofuran, cimoxanil, mancozeb e oxicloreto de cobre. As irrigações foram por aspersão convencional, no período da manhã, com uma lâmina de água estabelecida a partir da estimativa da evapotranspiração de referência e do coeficiente de cultura (Kc). A estimativa de evapotranspiração de referência foi realizada pelo método de Penman-Monteith, proposto pela FAO (Allen, 1993), mantendo-se o solo com umidade próxima à capacidade de campo.

Aos 21 dias após a emergência (DAE) foi determinado o índice SPAD, obtido com o medidor portátil SPAD-502, em medição feita no folíolo terminal da quarta folha a partir do ápice da planta (QF), em seis plantas de cada parcela, entre 8 e 11 h. Em cada folha efetuaram-se cinco leituras, a partir das quais foi obtida a média para cada folha amostrada. A média das seis leituras representou o valor da parcela. $\mathrm{Na}$ mesma data, foram coletados dois discos foliares do folíolo terminal da quarta folha de uma planta representativa de cada parcela. Os discos foram congelados em $\mathrm{N}$ líquido, posteriormente pesados e homogenizados num almofariz com $\mathrm{CaCO}_{3}$ areia e $5 \mathrm{~mL}$ de acetona $80 \%$. Esse extrato foi filtrado, coletando-se o filtrado num balão de $25 \mathrm{~mL}$ revestido com papel-alumínio, e completado o volume. Os teores de clorofilas totais foram quantificados pelo método espectrofotométrico (Lichthenthaler, 1987).

Também aos 21 DAE, uma planta representativa de cada parcela foi colhida, entre 8 e $11 \mathrm{~h}$ do dia seguinte à irrigação da cultura. No laboratório, as folhas foram colocadas em estufa a $70{ }^{\circ} \mathrm{C}$, até atingirem massa constante, para obtenção da massa da matéria seca. Esta foi triturada em moinho tipo Wiley para determinação do teor de $\mathrm{N}-\mathrm{NH}_{4}{ }^{+}$após digestão sulfúrica, utilizando-se o reagente de Nessler (Jackson, 1958). Em outra subamostra foi extraído o $\mathrm{N}-\mathrm{NO}_{3}{ }^{-}$com água desmineralizada, em banho-maria, a $45{ }^{\circ} \mathrm{C}$ por uma hora, determinando-se a concentração de $\mathrm{N}-\mathrm{NO}_{3}{ }^{-}$por colorimetria, em espectrofotômetro a $410 \mathrm{~nm}$, segundo método de Cataldo et al. (1975). O teor de N-total foi obtido pela soma do teor de $\mathrm{N}-\mathrm{NO}_{4}{ }^{+}$ com o N-NO${ }_{3}^{-}$.

Aos 22 DAE foi feita a amontoa. Aos 95 DAE, com as ramas completamente secas, as plantas foram colhidas e os tubérculos arrancados. Estes permaneceram sobre o solo por $2 \mathrm{~h}$ para o secamento da película, sendo posteriormente levados para um galpão, onde foram separados em comerciais e não comerciais, contados e pesados. Os tubérculos comerciais foram classificados de acordo com as normas do Ministério da Agricultura, Pecuária e Abastecimento (Brasil, 1995), em função do seu maior diâmetro transversal, em: classe 1 (diâmetro maior ou igual a $8,5 \mathrm{~cm}$ ); classe 2 (maior que 4,5 e menor que $8,5 \mathrm{~cm}$ ); classe 3 (maior que 3,3 e menor que $4,5 \mathrm{~cm}$ ); e classe 4 (menor ou igual a $3,3 \mathrm{~cm})$. A produção comercial foi obtida somando-se as classes
1, 2 e 3. Os tubérculos não comerciais foram considerados aqueles pertencentes à classe 4, além dos podres, atacados por pragas e doenças, com defeitos de esverdeamento, embonecamento ou rachaduras.

Os dados foram submetidos à análise de variância e regressão, utilizando-se o software estatístico SAEG (Ribeiro Júnior, 2001). Os modelos de regressão testados foram: lineares, quadráticos e raiz-quadrático. Escolheu-se o modelo com base no significado biológico, na significância dos coeficientes de regressão, pelo teste t, e no maior coeficiente de determinação.

A dose de $\mathrm{N}$ que proporcionou a máxima produção física (MEF) foi obtida igualando-se a zero a primeira derivada da equação de resposta da produção comercial de tubérculos às doses de $\mathrm{N}$. A dose de $\mathrm{N}$ que proporcionou a máxima eficiência econômica (MEE) foi obtida igualando-se a primeira derivada da equação de resposta da produção comercial de tubérculos às doses de $\mathrm{N}$ à relação entre o preço médio do $\mathrm{N}$ contido na ureia e o preço da batata $(\$ / \mathrm{kg}: \$ / \mathrm{kg})$ nos últimos seis anos (jan/2003 a nov/2008) obtidos junto ao Instituto de Economia Agrícola de São Paulo. A relação média de preços foi igual a 1,91, referente ao preço da batata de $\mathrm{R} \$ 0,67 \mathrm{~kg}^{-1}$ e ao preço do $\mathrm{N}$ na forma de ureia de $\mathrm{R} \$ 1,28 \mathrm{~kg}^{-1}$.

Foi calculado o valor do nível crítico $(\mathrm{NC})$ para o índice SPAD e para o teor de $\mathrm{N}$ na quarta folha a partir do ápice da batateira associado à dose de $\mathrm{N}$ que propiciou a máxima eficiência econômica (MEE), substituindo esse valor na equação ajustada das referidas características.

\section{RESULTADOS E DISCUSSÃO}

Não houve interação entre doses de $\mathrm{N}$ e cultivares de batata para as características produção total e comercial de tubérculos de batata (Quadro 2). Tanto a produtividade comercial quanto a produtividade total de tubérculos aumentaram significativamente com o incremento das doses de N, seguindo o modelo quadrático para ambas as cultivares (Figura 1).

As doses de 289 e $261 \mathrm{~kg}^{-1}$ de $\mathrm{N}$ proporcionaram as máximas produtividades total de tubérculos para as cultivares Ágata e Asterix, respectivamente. Para essas cultivares, a máxima produtividade comercial de tubérculos foi de 45.065 e $46.500 \mathrm{~kg} \mathrm{ha}^{-1}$, obtidas com as doses de 297 e $250 \mathrm{~kg} \mathrm{ha}^{-1}$ de N, respectivamente. Busato (2007), em trabalho realizado na mesma região do presente experimento com as cultivares Ágata e Asterix na época das secas, obteve produtividade comercial máxima de 33,1 e 32,3 t ha-1 com as doses de 168 e $212 \mathrm{~kg} \mathrm{ha}^{-1}$ de $\mathrm{N}$, respectivamente, utilizando o sulfato de amônio como fonte. Diferenças no rendimento dos tubérculos entre diferentes anos foram reportadas por Rodrigues et al. (2005), principalmente nas parcelas controle, e justificadas pela diferença no teor de $\mathrm{N}$ disponível no solo. 
Quadro 2. Resumo da análise de variância para as produtividades total e comercial ( $\left.\mathrm{kg} \mathrm{ha}^{-1}\right)$, teor de N (g kg-1), índice SPAD e teor de clorofila $\left(\mathrm{mg} \mathrm{g}^{-1}\right)$ na quarta folha da batateira de acordo com os tratamentos

\begin{tabular}{|c|c|c|c|c|c|c|}
\hline \multirow{2}{*}{$\begin{array}{l}\text { Fonte de } \\
\text { variação }\end{array}$} & \multirow{2}{*}{ GL } & \multicolumn{4}{|c|}{ Quadrado médio (significância) } & \multirow{2}{*}{$\begin{array}{l}\text { Teor de } \\
\text { Clorofila }\end{array}$} \\
\hline & & $\begin{array}{c}\text { Produtividade } \\
\text { total }\end{array}$ & $\begin{array}{c}\text { Produtividade } \\
\text { comercial }\end{array}$ & Teor de N & Índice SPAD & \\
\hline Cultivar (A) & 1 & $20870096^{\mathrm{ns}}$ & $13349112^{\mathrm{ns}}$ & $469,4^{* *}$ & $86,5^{* *}$ & $7,0 * *$ \\
\hline Doses (B) & 3 & $148514282^{* *}$ & $158463173^{* *}$ & $794,3 * *$ & $98,2^{* *}$ & $7,1^{* *}$ \\
\hline $\mathrm{A} \times \mathrm{B}$ & 3 & $3225975^{\mathrm{ns}}$ & $8723656^{\mathrm{ns}}$ & $20,6^{\mathrm{ns}}$ & $4,3^{*}$ & $0,3 \mathrm{~ns}$ \\
\hline Bloco & 3 & $45132935^{\mathrm{ns}}$ & $37369725^{\mathrm{ns}}$ & $18,3^{\mathrm{ns}}$ & $0,2^{\mathrm{ns}}$ & $0,9 \mathrm{~ns}$ \\
\hline Resíduo & 21 & 25292948 & 30970163 & 18 & 1,2 & 0,6 \\
\hline Média geral & & 44482,5 & 41071,6 & 60,9 & 39,6 & 5,7 \\
\hline CV $(\%)$ & & 11,3 & 13,6 & 7 & 3 & 13 \\
\hline
\end{tabular}

**, * $\mathrm{e}^{\mathrm{ns}}$ : significativos a 1 e $5 \%$ e não significativo, respectivamente, para teste $\mathrm{F}$.

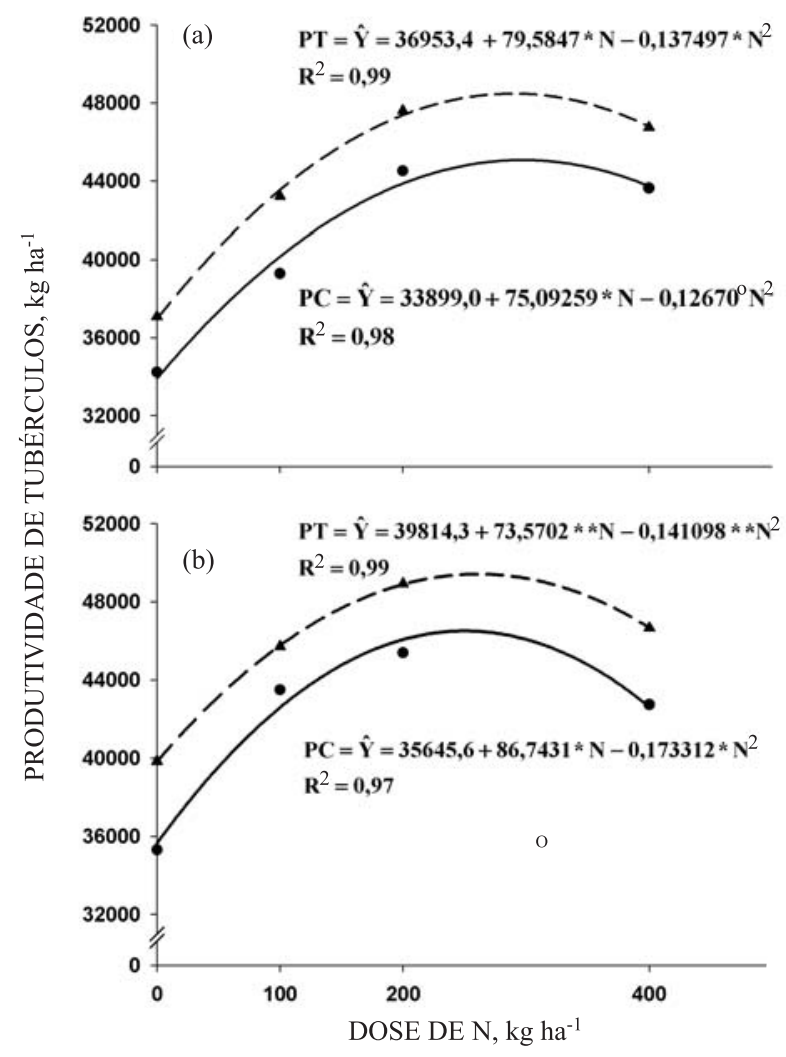

Figura 1. Produtividades total e comercial, em $\mathrm{kg} \mathrm{ha}^{-1}$, de tubérculos de batata cv. Ágata (a) e Asterix (b), em função das doses de nitrogênio. **, * $\mathrm{e}^{\circ}$ : significativo a 1,5 e $10 \%$, respectivamente, pelo teste $t$.

De maneira geral, doses de $\mathrm{N}$ variando de 30 a $350 \mathrm{~kg} \mathrm{ha}{ }^{-1}$ são recomendadas para o cultivo de batata irrigada em diversas regiões do mundo (Williams \& Maier, 1990). Nos países da Europa e nos Estados Unidos, a dose de $\mathrm{N}$ recomendada varia de 70 a $330 \mathrm{~kg} \mathrm{ha}^{-1}$, com ciclo de cultivo em torno de cinco meses (Kolbe \& Beckmann, 1997), e, no Canadá, de 165 a $215 \mathrm{~kg} \mathrm{ha}^{-1}$ (Zebarth et al., 2004). No Brasil, é possível encontrar recomendações de fertilização variando de 60 a $250 \mathrm{~kg} \mathrm{ha}^{-1}$ de N (Fontes, 1999).
Considerando-se relações mais e menos favoráveis de preço de tubérculos e adubo nitrogenado, no período compreendido entre janeiro de 2003 a novembro de 2008, a dose de N para obtenção da máxima eficiência econômica (MEE) variou de 283 a $293 \mathrm{~kg} \mathrm{ha}^{-1}$ de N para Ágata. Para a cultivar Asterix, a dose de $\mathrm{N}$ variou de 240 a $247 \mathrm{~kg} \mathrm{ha}^{-1}$ (Quadro 3).

Nas condições edafoclimáticas estudadas, considerando as máximas produções comerciais (física e econômica) e a relação média de preços do $\mathrm{N}$ e de tubérculos de batata, seria possível reduzir a dose de $\mathrm{N}$ em 7,35 e 5,24 $\mathrm{kg} \mathrm{ha}^{-1}$, ou seja, 2,5 e 2,1\% de economia na quantidade de $\mathrm{N}$, que representam $\mathrm{R} \$$ 9,41 e $\mathrm{R} \$ 6,71 \mathrm{ha}^{-1}$, para as cultivares Ágata e Asterix, respectivamente. Com a dose de 297 (MEF) ou de $290 \mathrm{~kg} \mathrm{ha}^{-1}$ de N (MEE), a produtividade comercial estimada de tubérculos de Ágata seria de 45.065 ou $45.057 \mathrm{~kg} \mathrm{ha}^{-1}$, respectivamente. Para Asterix, com a dose de 250 ou $245 \mathrm{~kg} \mathrm{ha}^{-1}$ de $\mathrm{N}$, a produtividade comercial estimada de tubérculos seria de 46.500 ou $46.495 \mathrm{~kg} \mathrm{ha}^{-1}$, respectivamente. Isso significa redução de menos de $0,02 \%$ na produção comercial das duas cultivares com a utilização das doses de 290 e $245 \mathrm{~kg} \mathrm{ha}^{-1}$ de $\mathrm{N}$, respectivamente.

Não houve interação significativa entre o teor de N-total na quarta folha a partir do ápice $(\mathrm{QF})$ e cultivares de batata (Quadro 2); o modelo quadrático foi o que melhor descreveu o efeito de doses de $\mathrm{N}$ sobre

Quadro 3. Doses de nitrogênio $\left(\mathrm{kg} \mathrm{ha}^{-1}\right)$ para obtenção da máxima eficiência econômica da produção de tubérculos de cultivares de batata em três cenários de relação de preços do nitrogênio e da batata

\begin{tabular}{cccc}
\hline \multirow{2}{*}{ Cultivar } & \multicolumn{2}{c}{ Relação de preço do N/Preço da batata } \\
\cline { 2 - 4 } & Baixa (1,13) & Média (1,90) & Alta (3,49) \\
\hline Ágata & 293 & 290 & 283 \\
Asterix & 247 & 245 & 240 \\
\hline
\end{tabular}


o teor de N-total na QF (Figura 2). Acréscimos nas concentrações de $\mathrm{N}$ na folha têm sido detectados com o aumento da quantidade da adubação nitrogenada. Os aumentos tendem a atingir variações pronunciadas, que decrescem à medida que aumenta a quantidade do fertilizante aplicado (White \& Sanderson, 1983).

$\mathrm{O}$ nível crítico do teor de $\mathrm{N}$ na matéria seca da $\mathrm{QF}$ associado à dose de $\mathrm{N}$ que propiciou a produção de máxima eficiência econômica foi de $66,7 \mathrm{~g} \mathrm{~kg}^{-1}$ para Ágata e 75,2 $\mathrm{g} \mathrm{kg}^{-1}$ para Asterix. Gil et al. (2002) verificaram que o teor de $\mathrm{N}$ na matéria seca da quarta folha da batata no campo também aumentou de maneira quadrática com o incremento das doses de $\mathrm{N}$ em pré-plantio, encontrando valor de $61,5 \mathrm{~g} \mathrm{~kg}^{-1}$ para a dose de $\mathrm{N}$ que propiciou a maior produção de tubérculos comerciais. Valores de 40 a $65 \mathrm{~g} \mathrm{~kg}^{-1}$ de $\mathrm{N}$ na matéria seca da folha completamente desenvolvida de batateira jovem são citados como adequados (Rodrigues et al., 2000). O uso do nível crítico na interpretação de resultados de análise foliar deve ser feito tomando algumas precauções, considerando cultivar, época de amostragem e de aplicação do fertilizante, entre outras (Fontes, 2001).

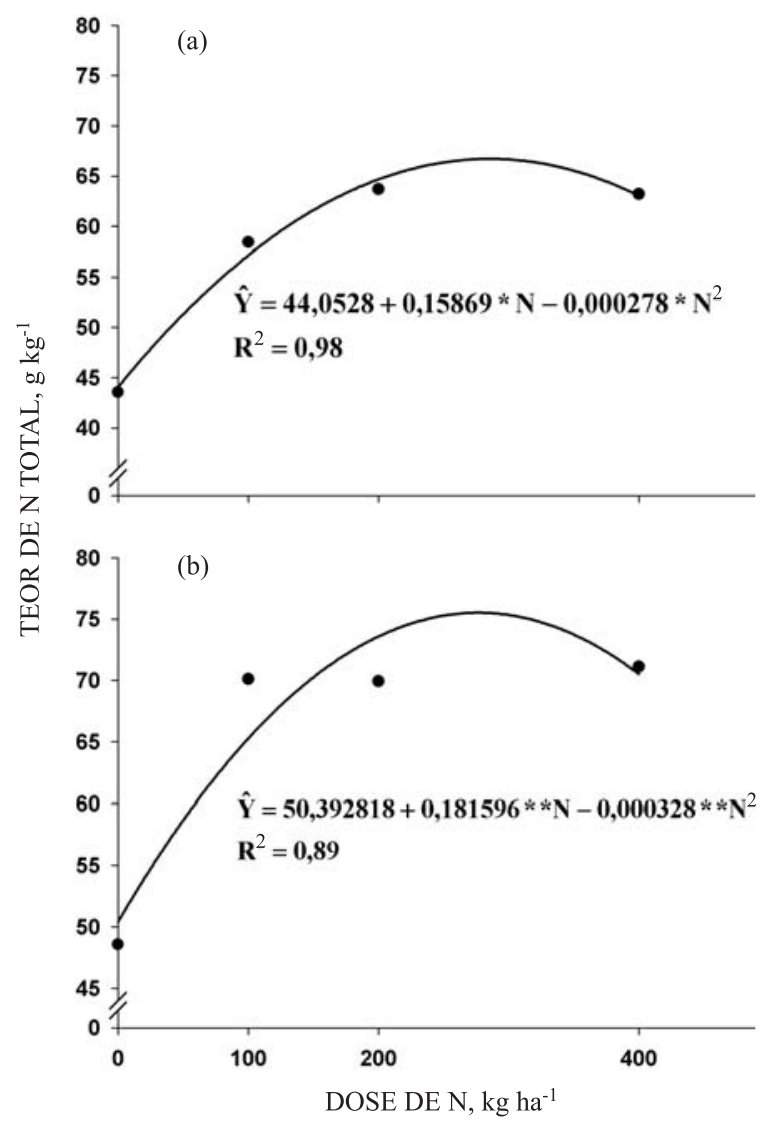

Figura 2. Teor de N-total medido na quarta folha a partir do ápice da batateira aos 21 DAE para as cultivares Ágata (a) e Asterix (b), em função das doses de nitrogênio. $* *, * \mathrm{e}^{\circ}$ : significativo a $1,5 \mathrm{e}$ $10 \%$, respectivamente, pelo teste $t$.
Houve interação significativa entre doses de $\mathrm{N}$ e cultivares para índice SPAD (Quadro 2), com efeito quadrático em função das doses de N para Ágata e raiz-quadrático para Asterix (Figura 3). O clorofilômetro não detecta o consumo de luxo de $\mathrm{N}$ (Blackmer \& Schepers, 1994), ou seja, quando se trabalha com altas doses de N, o índice SPAD na folha tende a aumentar até certo ponto, chamado de ponto de maturidade fotossintética (Costa et al., 2001), a partir do qual se mantém invariável, enquanto o teor de $\mathrm{N}$ continua aumentando com as doses crescentes desse nutriente (Schepers et al., 1992). Isso pode ser atribuído ao fato de o aparelho detectar, indiretamente, o aumento de $\mathrm{N}$ apenas quando está sendo incorporado em moléculas de clorofila e não na forma livre, não incorporada $\left(\mathrm{N}-\mathrm{NO}_{3}^{-}\right)$, na qual o $\mathrm{N}$ se acumula quando há consumo de luxo (Larcher, 2000).

O nível crítico correspondente ao índice SPAD, para a dose de $\mathrm{N}$ que propiciou a máxima eficiência econômica, foi de 40,5 para Ágata e 43,7 para Asterix. Malavolta et al. (1997) citam a faixa de 49 a 56 como adequada para o índice SPAD na quarta ou quinta folha mais nova totalmente expandida a partir do ápice, amostrada um mês depois do plantio em campo. Busato (2007) obteve o nível crítico do índice SPAD de 43 e 50 na quarta folha jovem completamente expandida das cultivares Ágata e Asterix, respectivamente, aos 21 DAE. O SPAD-502, mesmo com sistema de compensação (luz absorvida no comprimento de onda de $940 \mathrm{~nm}$ ) para alterações na espessura e conteúdo de água da folha, apresenta variações de leitura entre espécies de plantas (Richardson et al., 2002) e entre genótipos de uma mesma espécie (Bullock \& Anderson, 1998) cultivados em uma mesma condição de ambiente, devido a diferenças na estrutura e anatomia foliar.

O teor de clorofila na matéria fresca seguiu um modelo quadrático para ambas as cultivares (Figura 3). Há participação direta do N na constituição da clorofila, a qual tem no glutamato seu precursor inicial. O glutamato é um composto nitrogenado que, além de ser o precursor de outros aminoácidos essenciais, é também o precursor do ácido $\delta$-aminolevulínico (ALA), que por sua vez é considerado precursor universal dos tetrapirrólicos. Assim, a deficiência de $\mathrm{N}$ leva à redução na síntese do glutamato, ALA e na atividade da porfobilinogênio sintase e, como consequência, a uma queda na biossíntese de clorofila, o que leva ao desenvolvimento da clorose nas plantas (Chu et al., 2006).

O nível crítico do teor de clorofila associado à máxima eficiência econômica foi de 6,13 e 6,96 $\mathrm{mg} \mathrm{g}^{-1} \mathrm{de}$ matéria fresca, para Ágata e Asterix, respectivamente. Os resultados das leituras com o SPAD-502 correlacionaram-se positivamente com os teores de clorofila total (TCL), podendo ser descritos pelas equações: TCL $\left(\mathrm{mg} \mathrm{g}^{-1}\right)=0,218$ SPAD - 3,0420 $\left(\mathrm{r}^{2}=0,47^{* *}\right)$, para a cultivar Ágata; e TCL $\left(\mathrm{mg} \mathrm{g}^{-1}\right)=0,222$ SPAD $\times 3,0220\left(\mathrm{r}^{2}=0,43^{* *}\right)$, para a cultivar Asterix. Em 


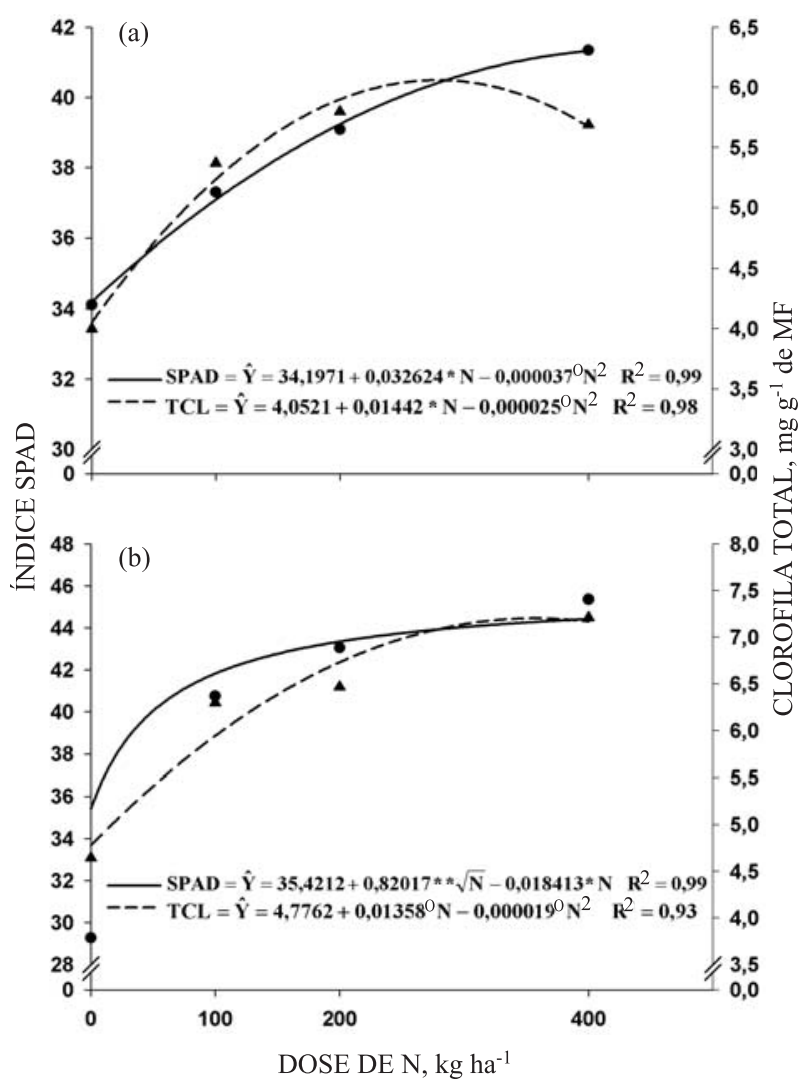

Figura 3. Índice SPAD e teor de clorofila medido na quarta folha a partir do ápice da batateira aos 21 DAE para as cultivares Ágata (a) e Asterix (b), em função das doses de nitrogênio. $* *, \mathrm{e}^{\circ}$ : significativo a 1,5 e $10 \%$, respectivamente, pelo teste $t$.

situações em que a disponibilidade de $\mathrm{N}$ é grande, as leituras do SPAD-502 e o conteúdo de clorofila são pouco correlacionados, uma vez que o potencial do sistema fotossintético já se encontra estabelecido e atuante na conversão de energia luminosa em energia química, e o excedente de $\mathrm{N}$ encontra-se na forma de outros compostos de reserva (Argenta et al., 2001).

Utilizando os 16 pares de dados, verifica-se que houve correlação linear positiva entre as características analisadas na QF da batateira e a produção comercial de tubérculos (Quadro 4). Os valores de índice SPAD apresentaram coeficiente de correlação com a produção de tubérculos de $0,59 * *$ e $0,54 * *$, para as cultivares Ágata e Asterix, respectivamente. Gil et al. (2002) também encontraram correlação de 0,62 entre o valor de índice SPAD e a produção de tubérculos de batata. Em avaliação feita durante o ciclo da cultura do milho, Piekielek \& Fox (1992) observaram que os valores SPAD na folha correlacionaram-se com a quantidade de $\mathrm{N}$ adicionada e com a produção de grãos. O aumento do valor do índice SPAD devido à adubação nitrogenada mostra a relação entre o $\mathrm{N}$ e a intensidade de cor verde da planta, a maior síntese de clorofila (Taiz \& Zeiger, 2009) e o aumento da ativida- de fotossintética, possibilitando o aumento da produção (Stone et al., 2002). Além disso, o clorofilômetro SPAD tem a capacidade de detectar o aparecimento da deficiência de $\mathrm{N}$ antes que seja visível ao olho humano e cedo o suficiente para corrigir essa deficiência, sem redução na produtividade (Samborski et al., 2009), desde que não haja interrupção indesejada do ciclo e outros fatores não se tornem limitantes.

Quadro 4. Correlações lineares de Pearson (r) entre produção total (PT), produção comercial (PC), índice SPAD, teor de nitrogênio (TN) e teor de clorofila (TCL) da batata cv. Ágata e Asterix

\begin{tabular}{|c|c|c|}
\hline Correlação & $\mathbf{r}$ & Equação estimada \\
\hline \multicolumn{3}{|c|}{ Ágata } \\
\hline SPAD com PT & $0,63^{* *}$ & $\mathrm{PT}=-4500,4+1269,10 \mathrm{SPAD}$ \\
\hline SPAD com PC & $0,59 * *$ & $\mathrm{PC}=-7048,4+1250,59 \mathrm{SPAD}$ \\
\hline $\mathrm{TN}$ com $\mathrm{PT}$ & $0,64^{* *}$ & $\mathrm{PT}=19054,8+430,20 \mathrm{TN}$ \\
\hline $\mathrm{TN}$ com PC & $0,60 * *$ & $\mathrm{PC}=16096,8+425,11 \mathrm{TN}$ \\
\hline TCL com PT & $0,42^{*}$ & $\mathrm{PT}=29672,7+2684,6 \mathrm{TCL}$ \\
\hline TCL com PC & $0,35^{*}$ & $\mathrm{PC}=28156,5+2352,4 \mathrm{TCL}$ \\
\hline \multicolumn{3}{|c|}{ Asterix } \\
\hline SPAD com PT & $0,50 * *$ & $\mathrm{PT}=10397,2+845,89 \mathrm{SPAD}$ \\
\hline SPAD com PC & $0,54^{* *}$ & $\mathrm{PC}=828,39+991,26 \mathrm{SPAD}$ \\
\hline $\mathrm{TN}$ com PT & $0,40 *$ & $\mathrm{PT}=30096,3+233,96 \mathrm{TN}$ \\
\hline $\mathrm{TN}$ com PC & $0,40^{*}$ & $\mathrm{PC}=25527,3+249,30 \mathrm{TN}$ \\
\hline TCL com PT & $0,40^{*}$ & $\mathrm{PT}=32698,6+2045,7 \mathrm{TCL}$ \\
\hline TCL com PC & $0,32^{*}$ & $\mathrm{PC}=30843,5+1766,7 \mathrm{TCL}$ \\
\hline
\end{tabular}

\section{CONCLUSÕES}

1. O rendimento de tubérculos de batata aumentou com as doses de $\mathrm{N}$ aplicadas, atingindo valores máximos de 45.065 e $46.500 \mathrm{~kg} \mathrm{ha}^{-1}$, com as doses de 297 e $250 \mathrm{~kg} \mathrm{ha}^{-1}$ de N para as cultivares Ágata e Asterix, respectivamente. Para as mesmas cultivares, as doses de $\mathrm{N}$ associadas à máxima eficiência econômica foram de 290 e $245 \mathrm{~kg} \mathrm{ha}^{-1}$, respectivamente.

2. Houve efeito de doses de $\mathrm{N}$ sobre o índice SPAD e os teores de $\mathrm{N}$ e clorofila na quarta folha a partir do ápice. O nível crítico do índice SPAD associado com a dose de $\mathrm{N}$ que propiciou a máxima eficiência econômica foi de 40,5 e 43,7 para as cultivares Ágata e Asterix, respectivamente.

3. As leituras realizadas com o clorofilômetro correlacionaram-se positivamente com o teor de clorofila extraível, mostrando que este pode ser utilizado para estimar o teor de clorofila em folhas de batata. 
4. Houve correlação linear e positiva entre os valores do índice SPAD e os da produção de tubérculos de batata, indicando que há boa perspectiva no seu uso para o prognóstico da produtividade.

\section{AGRADECIMENTOS}

À FAPEMIG e ao CNPq, pelo apoio financeiro.

\section{LITERATURA CITADA}

ALLEN, R.G. New approaches to estimating crop evapotranspiration. Acta Hortic., 335:287-293, 1993.

ARGENTA， G.; SILVA, P.R.F.; BARTOLINI, C.G.; FORSTHOFER, E.L. \& STRIEDER, M.L. Relação da leitura do clorofilômetro com os teores de clorofila extraível e nitrogênio nas folhas de milho. R. Bras. Fisiol. Veg., 13:158-167, 2001.

AZIA, F. \& STEWART, K.A. Relationships between extractable chlorophyll and SPAD values in muskmelon leaves. J. Plant. Nutr., 24:961-966, 2001.

BÉLANGER, G.; WALSH, J.R.; RICHARDS, J.E.; MILBURN, P.H. \& ZIADI, N. Comparison of three statistical models describing potato yield response to nitrogen fertilizer. Agron. J., 92:902-908, 2000.

BLACKMER, T.M. \& SCHEPERS, J.S. Techniques for monitoring crop nitrogen status in corn. Comm. Soil Sci. Plant Anal., 25:1791-1800, 1994.

BRASIL. Ministério da Agricultura, Pecuária e Abastecimento. Norma de identidade, qualidade, acondicionamento e embalagem da batata para fins de comercialização. Portaria $\mathrm{n}^{\circ} 69$ de 21 de fevereiro de 1995.

BULLOCK, D.G. \& ANDERSON, D.S. Evaluation of the Minolta SPAD-502 chlorophyll meter for nitrogen management in corn. J. Plant. Nutr., 21:741-755, 1998.

BUSATO, C. Características da planta, teores de nitrogênio na folha e produtividade de tubérculos de cultivares de batata em função de doses de nitrogênio. Viçosa, MG, Universidade Federal de Viçosa, 2007. 129p. (Tese de Mestrado)

CATALDO, D.A.; HAROON, M.; SCHRADER, L.E. \& YOUNES, V.L. Rapid colorimetric determination of nitrate in plant tissue by nitration of salicylic acid. Comm. Soil Sci. Plant Anal., 6:71-80, 1975.

COELHO, E.L. \& FONTES, P.C.R. Índices agronômicos do meloeiro associado à dose adequada de nitrogênio, em ambiente protegido e no campo. Ci. Agrotec., 29:974-979, 2005 .

COSTA, C.; DWYER, L.M.; DUTILLEUL, P.; STEWART, D.W.; MA, B.L. \& SMITH, D.L. Inter-relationships of applied nitrogen, spad, and yield of leafy and non-leafy maize genotypes. J. Plant. Nutr., 24:1173-1194, 2001.
EMPRESA BRASILEIRA DE PESQUISA AGROPECUÁRIA EMBRAPA. Centro Nacional de Pesquisa de Solos. Sistema brasileiro de classificação de solo. Rio de Janeiro, Embrapa Solos, 1999. 412p.

FONTES, P.C.R. Calagem e adubação da cultura da batata. Inf. Agropec., 20:42-52, 1999

FONTES, P.C.R. Diagnóstico do estado nutricional das plantas. Viçosa, MG, Universidade Federal de Viçosa, 2001. 122p.

FONTES, P.C.R. Cultura da batata. In: FONTES, P.C.R., ed. Olericultura: Teoria e prática. Viçosa, MG, Universidade Federal de Viçosa, 2005. p.323-343.

FONTES, P.C.R. \& ARAÚJO, C. Adubação nitrogenada de hortaliças: Princípios e práticas com o tomateiro. Viçosa, MG, Universidade Federal de Viçosa, 2007. 148p.

GIL, P.T. Índices e eficiência de utilização de nitrogênio pela batata influenciados por doses de nitrogênio em pré-plantio e em cobertura. Viçosa, MG, Universidade Federal de Viçosa, 2001. 81p. (Tese de Mestrado)

GIL, P.A.; FONTES, P.C.R.; CECON, P.R. \& FERREIRA, F.A. Índice SPAD para o diagnóstico do estado de nitrogênio e para o prognóstico da produtividade da batata. Hortic. Bras., 20:611-615, 2002.

JACKSON, M.L. Soil chemical analysis. Englewood Cliffs, Prentice Hall, 1958. 498p.

KofPPEn, W. Climatologia. Tradução: Pedro R. H. Perez. Buenos Aires, Panamericana, 1948. 478p.

KOLBE, H. \& BECKMANN, S.E. Development, growth and chemical composition of the potato crop (Solanum tuberosum L.). I. leaf and stem. Potato Res., 40:111-129, 1997.

LARCHER, W. Ecofisiologia vegetal. São Carlos, RiMa, 2000. $531 \mathrm{p}$.

LICHTHENTHALER, H.K. Chlorophylls and carotenoids: pigments of photosynthetic biomembranes. In: COLOWICK, S.P. \& KAPLAN, N.O., eds. Methods in enzimology. San Diego, Academic Press, 1987. v.148. p.350382.

MADEIRA, A.C.; MENDONÇA, A.; FERREIRA, M.E. \& TABORDA, M. Relationship between spectroradiometric and chlorophyll measurements in green beans. Comm. Soil Sci. Plant Anal., 31:631-643, 2000.

MALAVOLTA, E.; VITTI, G.C. \& OLIVEIRA, S.A. Avaliação do estado nutricional das plantas: Princípios e aplicações. 2.ed. Piracicaba, Associação Brasileira para Pesquisa da Potassa e do Fosfato, 1997. 319p.

NEVES, O.S.C.; CARVALHO, J.G.; MARTINS, F.A.D.; PÁDUA, T.R.P. \& PINHO, P.J. Uso do SPAD-502 na avaliação dos teores foliares de clorofila, nitrogênio, enxofre, ferro e manganês do algodoeiro herbáceo. Pesq. Agropec. Bras., 40:517-521, 2005 .

PIEKIELEK, W.P. \& FOX, R.H. Use of a chlorophyll meter to predict sidedress nitrogen requirements for maize. Agron. J., 84:59-65, 1992. 
RIBEIRO JÚNIOR, J.I. Análises estatísticas no SAEG. Viçosa, MG, Universidade Federal de Viçosa, 2001. 301p.

RICHARDSON, A.D.; DUIGAN, S.P. \& BERLYN, G.P. An evaluation of noninvasive methods to estimate foliar chlorophyll content. New Phytol., 153:185-194, 2002.

RODRIGUES, F.A.; FONTES, P.C.R.; PEREIRA, P.R.G. \& MARTINEZ, H.E.P. Crescimento e teor crítico de $\mathrm{N}^{-\mathrm{NO}_{3}}$ na seiva da batateira cultivada em solução nutritiva. Hortic. Bras., 18:766-767, 2000.

RODRIGUES, M.A.; COUTINHO, J.; MARTINS, F. \& ARROBAS, M. Quantitative sidedress nitrogen recommendations for potatos based upon crop nutritional indices. Europ. J. Agron., 23:79-88, 2005.

SAMBORSKI, S.M.; TREMBLAY, N. \& FALLON, E. Strategies to make use of plant sensors-based diagnostic information for nitrogen recommendations. Agron. J., 101:800-816, 2009.

SAMDUR, M.Y.; SINGH, A.L.; MATHUR, R.K.; MANIVEL, P.; CHIKANI, B.M.; GOT, H.K. \& KHAN, M.A. Field evaluation of chlorophyll meter for screening groundnut (Arachis hypogaea L.) genotypes tolerant to irondeficiency chlorosis. Curr. Sci., 79:211-214, 2000.

SCHEPERS, J.S.; FRANCIS, D.D.; VIGIL, M. \& BELOW, F.E. Comparison of corn leaf nitrogen concentration and chlorophyll meter reading. Comm. Soil Sci. Plant Anal., 23:2173-2187, 1992

STONE, L.F.; SILVA, G.M.E. \& MOREIRA, J.A.A. Uso do clorofilômetro SPAD-502 na estimativa do nitrogênio foliar específico e da produtividade do feijoeiro. In: CONGRESSO NACIONAL DE PESQUISA DE FEIJÃO, 7., Viçosa, MG, 2002. Resumos... Viçosa, MG, Universidade Federal de Viçosa, 2002. p.743-746.
TAIZ, L. \& ZEIGER, E. Fisiologia vegetal. 4.ed. Porto Alegre, Artmed, 2009. 848p.

VOS, J. \& BOM, M. Hand-held chlorophyll meter: A promising tool to asses the nitrogen status of potato foliage. Potato Res., 36:301-308, 1993.

WHITE, R.P. \& SANDERSON, J.B. Effect of planting date, nitrogen rate, and plant spacing on potatoes grown for processing in Prince Edward Island. Am. Potato J., 60:115126, 1983.

WILLIAMS, C.M.J. \& MAIER, N.A. Determination of the nitrogen status of irrigated potato crops. I. Critical nutrient ranges for nitrate-nitrogen in petioles. J. Plant Nutr., 13:971-984, 1990.

YIN, X.; LANTINGA, E.A.; SHAPENDONK, H.C.M. \& ZHONG, $\mathrm{X}$. Some quantitative relationships between leaf area index and canopy nitrogen content and distribution. Ann. Bot., 91:893-903, 2003.

ZEBARTH, B.J.; TAI, G.; TARN, R.; JONG, H. \& MILBURN, P.H. Nitrogen use efficiency characteristics of commercial potato cultivars. Can. J. Soil Sci., 84:589-598, 2004.

ZVOMUYA, F.; ROSEN, C.J.; RUSSELLE, M.P. \& GUPTA, S.C. Nitrate leaching and nitrogen recovery following application of polyolefin-coated urea of potato. J. Environ. Qual., 32:480-489, 2003. 